\title{
Continuous Mesoporous Pd Films by Electrochemical Deposition in Nonionic Micellar Solution
}

\author{
Muhammad Iqbal, ${ }^{\dagger, \dagger}$ Cuiling Li, ${ }^{\dagger}$ Kathleen Wood, ${ }^{\S}$ Bo Jiang, ${ }^{\dagger}$ Toshiaki Takei, $^{\dagger}$ Ömer Dag, ${ }^{\|, \perp \mathbb{C}}$ \\ Daisuke Baba, ${ }^{\dagger}, \frac{\ddagger}{\dagger}$ Asep Sugih Nugraha, ${ }^{\dagger,}$ Toru Asahi, ${ }^{\ddagger}$ Andrew E. Whitten, ${ }^{\S}$ Md. Shahriar A. Hossain, ${ }^{\#}$ \\ Victor Malgras, ${ }^{\dagger}$ and Yusuke Yamauchi ${ }^{*}, \dagger,+, \#$ \\ ${ }^{\dagger}$ International Center for Materials Nanoarchitectonics (MANA), National Institute for Materials Science (NIMS), 1-1 Namiki, \\ Tsukuba, Ibaraki 305-0044, Japan \\ ${ }^{\ddagger}$ Faculty of Science and Engineering, Waseda University, 3-4-1 Okubo, Shinjuku, Tokyo 169-8555, Japan \\ ${ }^{\S}$ Australian Centre for Neutron Scattering, Australian Nuclear Science and Technology Organisation (ANSTO), Lucas Heights, New \\ South Wales 2234, Australia \\ "Department of Chemistry, Bilkent University, Ankara 06800, Turkey \\ ${ }^{\perp}$ UNAM-National Nanotechnology Research Center and Institute of Materials Science and Nanotechnology, Bilkent University, \\ Ankara 06800, Turkey \\ ${ }^{\#}$ Australian Institute for Innovative Materials (AIIM), University of Wollongong, Squires Way, North Wollongong, New South Wales \\ 2500, Australia
}

\section{Supporting Information}

ABSTRACT: Mesoporous metals that combine catalytic activity and high surface area can provide more opportunities for electrochemical applications. Various synthetic methods, including hard and soft templating, have been developed to prepare mesoporous/nanoporous metals. Micelle assembly, typically involved in soft-templates, is flexible and convenient for such purposes. It is, however, difficult to control, and the ordering is significantly destroyed during the metal deposition process, which is detrimental when it comes to designing

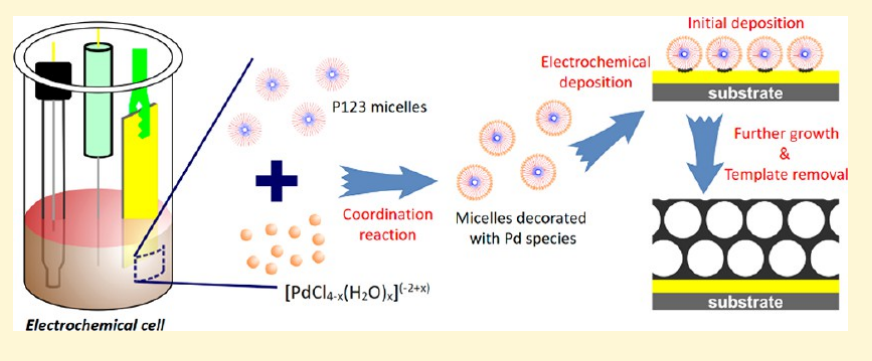
precisely mesostructured materials. In the present work, mesoporous Pd films were uniformly electrodeposited using a nonionic surfactant, triblock copolymer poly(ethylene oxide)- $b$-poly(propylene oxide)- $b$-poly(ethylene oxide), as a pore-directing agent. The interaction between micelles and metal precursors greatly influences the metal growth and determines the final structure. The water-coordinated species interact with the ethylene oxide moiety of the micelles to effectively drive the Pd(II) species toward the working electrode surface. From small-angle neutron scattering data, it is found that spherical P123 micelles, with an average diameter of $\sim 14 \mathrm{~nm}$, are formed in the electrolyte, and the addition of Pd ions does not significantly modify their structure, which is the essence of the micelle assembly approach. The uniformly sized mesopores are formed over the entire mesoporous Pd film and have an average pore diameter of $10.9 \mathrm{~nm}$. Cross-sectional observation of the film also shows mesopores spanning continuously from the bottom to the top of the film. The crystallinity, crystal phase, and electronic coordination state of the Pd film are also confirmed. Through this study, it is found that the optimized surfactant concentration and applied deposition potential are the key factors to govern the formation of homogeneous and well-distributed pores over the entire film. Interestingly, the as-prepared mesoporous $\mathrm{Pd}$ films exhibit superior electrocatalytic activity toward the ethanol oxidation reaction by fully utilizing the accessible active surface area. Our approach combines electrochemistry with colloidal and coordination chemistry and is widely applicable to other promising metals and alloy electrocatalysts.

\section{INTRODUCTION}

Because of their unique structural features, such as high surface area, large pore volume, and uniform pore size, mesoporous materials have shown great potential in many important applications (e.g., catalysis, drug delivery, sensing). ${ }^{1-5}$ In particular, mesoporous metals combining catalytic activity and high surface area provide more opportunities for enhancing electrocatalytic performances, including small molecule oxidation reaction, oxygen reduction reaction, or oxygen/hydrogen evolution reaction. ${ }^{6-10}$ To date, several applications using mesoporous noble metals (e.g., Pt, Pd, Au) have been demonstrated. Mesoporous $\mathrm{Pt}$ films ${ }^{6}$ and mesoporous $\mathrm{Pt} / \mathrm{Ru}$ nanoparticles ${ }^{8}$ exhibit strong catalytic activity and stability for the electrocatalysis of methanol oxidation reactions. Further-

Received: May 3, 2017

Revised: June 27, 2017

Published: July 17, 2017 
Scheme 1. Schematic Illustration of the Electrochemical Deposition of Mesoporous Pd Film from Aqeuous Solution Assisted by Nonionic Surfactant P123

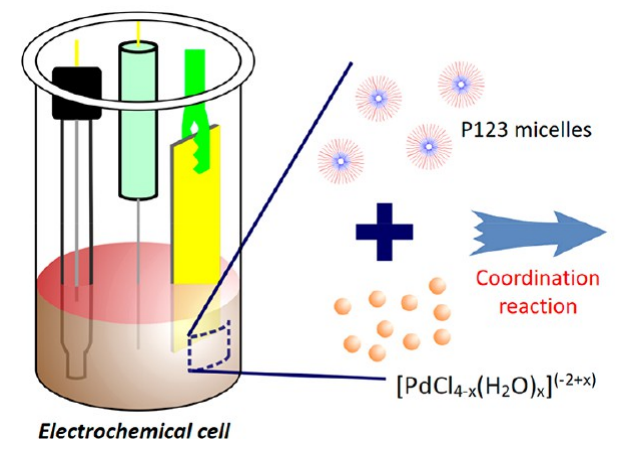

more, mesoporous Pd films show enhanced electrocatalytic performance for formic acid oxidation reaction by fully taking advantage of their large surface area. ${ }^{10}$ Various synthetic methods, including hard templating from mesoporous silica or alumina, ${ }^{11-13}$ dealloying, ${ }^{14-16}$ and soft-templating, ${ }^{6,10,17,18}$ have been developed to prepare mesoporous/nanoporous metals. Micelle assembly, typically involved in soft-templates, is flexible and convenient for the preparation of mesoporous metals under different conditions and greatly outperforms other methods. ${ }^{6,10}$ It is, however, difficult to control, and the ordering can be destroyed during the metal deposition process, which is detrimental when it comes to designing precisely mesostructured materials. Therefore, techniques involving micelle assembly must be improved to obtain desired mesoporous structures with fine precision.

In our previous study, we successfully synthesized mesoporous $\mathrm{Pd}$ films by using cetyltrimethylammonium chloride (CTAC) as pore-directing agent, which participates in the formation of intermediate $\mathrm{CTA}^{+} /\left[\mathrm{PdCl}_{4}\right]^{2-}$ during the reaction process. ${ }^{10}$ For well-constructed mesoporous metallic structures to be achieved, micelles based on different categories of surfactants (e.g., cationic, nonionic, anionic) have been selected for their specific affinities with the target materials. ${ }^{19-23}$ Until now, only cationic surfactants have been employed to direct the fabrication of mesoporous palladium (Pd), which is more abundant than platinum $(\mathrm{Pt})$ and represents a promising candidate for several applications. ${ }^{24-26}$ Although mass transport is already facilitated by making the metal mesoporous, it can be further improved by expanding the pore size. The diameter of the obtained mesopores is limited to less than $5 \mathrm{~nm}$ due to the small molecular weight of the pore-directing molecules, thereby greatly hindering its practical application. Nonionic surfactants with a large molecular weight have been specifically employed for tailoring the synthesis of large pore mesoporous metal oxides and carbon-based materials. ${ }^{27,28}$ If nonionic surfactants could be appropriately utilized for the preparation of mesoporous $\mathrm{Pd}$, it would undoubtedly contribute to enhance its catalytic performance. Herein, an electrochemical method is used to finely control the growth of mesoporous $\mathrm{Pd}$ using nonionic surfactants to finally obtain mesoporous Pd films (Scheme 1). The resulting mesoporous $\mathrm{Pd}$ film with large pores is promising for the electrocatalysis of the ethanol oxidation reaction.

\section{EXPERIMENTAL SECTION}

Chemicals. Pluronic P123, Pluronic F127, Brij 58, and Nafion perfluorinated resin solutions were obtained from Sigma. Palladium(II) chloride was purchased from Nacalai Tesque, Inc. Sulfuric acid,

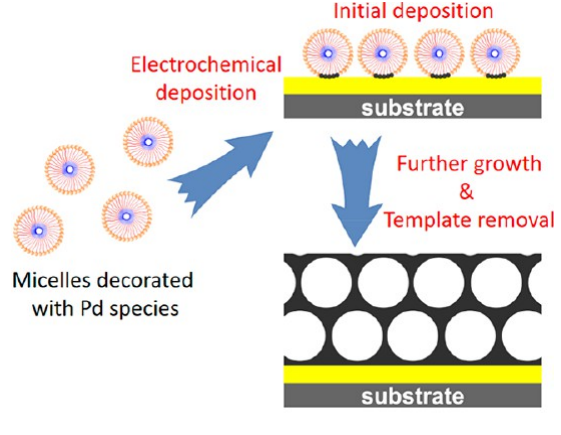

potassium hydroxide, and ethanol were obtained from Wako Chemicals. Palladium black was purchased from Alfa Aesar. All chemicals were used without further purification.

Electrochemical Deposition. Electrochemical deposition of mesoporous $\mathrm{Pd}$ films was conducted utilizing an electrochemical station (CHI 842B electrochemical analyzer, CHI Instruments, USA) with a standard three-electrodes cell system, including a $\mathrm{Ag} / \mathrm{AgCl}$ (3.0 $\mathrm{M} \mathrm{KCl}$ ), a platinum wire, and a gold-coated silicon wafer substrate as the reference, counter, and working electrodes, respectively. The electrolyte used during electrochemical deposition was prepared by dissolving 2.5 wt \% of Pluronic P123 in $40 \mathrm{mM} \mathrm{PdCl} 2$ aqueous solution. The electrodeposition of the Pd films was carried out at $0.0 \mathrm{~V}$ potential (vs $\mathrm{Ag} / \mathrm{AgCl})$ for $600 \mathrm{~s}$ without stirring at room temperature. Because P123 is water-soluble (solubility in water $>10$ wt $\%$ at $25{ }^{\circ} \mathrm{C}$ ), it can be easily removed from the films by rinsing with water. The asdeposited Pd films were then thoroughly rinsed with deionized water and dried under nitrogen gas flow before further characterization.

Characterization. Scanning electron microscope (SEM) imaging of the deposited Pd films were obtained using a Hitachi FESEM SU8000 microscope at an accelerating voltage of $5 \mathrm{kV}$. Transmission electron microscopy (TEM) was carried out using a JEOL JEM-2100F microscope at an accelerating voltage of $200 \mathrm{kV}$. The grazing-incidence small-angle X-ray scattering (GI-SAXS) pattern was recorded using a Rigaku NANO-Viewer (Microfocus rotating anode, $\mathrm{Cu} \mathrm{K} \alpha$ radiation) equipped with a camera length of $700 \mathrm{~mm}$, an operating voltage of 40 $\mathrm{kV}$, and a current of $30 \mathrm{~mA}$. Small-angle neutron scattering (SANS) was employed to characterize the micellar structure using the Bilby instrument at ANSTO. ${ }^{29}$ The instrument was used in time-of-flight mode using neutrons with wavelengths between 3.0 and $18.0 \AA(\Delta \lambda / \lambda$ $=12.0-16.0 \%$ ) with detectors positioned at 8.030 (rear), 2.030 (horizontal curtains), and $1.030 \mathrm{~m}$ (vertical curtains) from the sample. Two series of samples were measured with and without the addition of $\mathrm{PdCl}_{2}$ at 0.5 wt \% of $\mathrm{P} 123$ and at $40,60,80$, and $100 \% \mathrm{D}_{2} \mathrm{O}$. Round Hellma cells were used $\left(1 \mathrm{~mm}\right.$ path length for 40 and $60 \% \mathrm{D}_{2} \mathrm{O}$ or 2 $\mathrm{mm}$ for 80 and $100 \% \mathrm{D}_{2} \mathrm{O}$ ), and samples were measured at 25,30 , and $35{ }^{\circ} \mathrm{C}$. Data were reduced and put on an absolute scale relative to the direct beam using Mantid ${ }^{30}$ and then solvent subtracted. The Ultraviolet-Visible (UV-vis) spectra of the aqueous electrolyte solution used for electrochemical deposition were obtained with a JASCO V-7200. Low- and wide-angle X-ray diffraction (XRD) patterns of the as-deposited Pd films were obtained by Rigaku SmartLab XRD with $\mathrm{Cu} \mathrm{K} \alpha$ radiation. X-ray photoelectron spectroscopy (XPS) was carried out with a PHI Quantera SXM (ULVAC-PHI) with Al K $\alpha$ radiation to determine the composition and electronic coordination state of the as-prepared Pd films. All XPS spectra were calibrated to the $\mathrm{C} 1$ s peak at $285.0 \mathrm{eV}$.

Electrochemical Measurements. All electrochemical measurements were recorded with a $\mathrm{CHI} 842 \mathrm{~B}$ electrochemical analyzer (CHI Instruments, USA). A conventional three-electrode setup was employed to carry out the electrochemical measurements. A goldcoated silicon wafer substrate further coated with the Pd films, a Pt wire, and $\mathrm{Ag} / \mathrm{AgCl}$ or SCE electrodes were employed as the working, counter, and reference electrodes, respectively. The geometric area of 
the deposited Pd films on the gold-coated silicon wafer working electrode was $3 \mathrm{~mm} \times 6 \mathrm{~mm}$. As for electrochemical measurements of commercially available Pd black (denoted as PdB), a glassy carbon electrode (GCE) with a diameter of $3 \mathrm{~mm}$ was used as the working electrode. Prior to the $\mathrm{PdB}$ surface coating, the GCE was polished with 1.0 and $0.05 \mu \mathrm{m}$ alumina powder, rinsed with deionized water, and dried under nitrogen gas flow. Then, $5.0 \mu \mathrm{g}$ of $\mathrm{PdB}$ was coated on the surface of the GCE. After drying under atmospheric conditions, a Nafion solution $(5.0 \mu \mathrm{L}, 0.5$ wt \%) was subsequently coated on the GCE surface and dried at room temperature before further electrochemical measurements. Cyclic voltammograms were recorded in $0.5 \mathrm{M} \mathrm{H}_{2} \mathrm{SO}_{4}$ electrolyte at a scan rate of $50 \mathrm{mV} \mathrm{s}^{-1}$ between -0.2 and $+1.2 \mathrm{~V}$ (vs $\mathrm{Ag} / \mathrm{AgCl}$ ). The electrocatalytic performance toward the ethanol oxidation reaction was recorded in $1.0 \mathrm{M} \mathrm{KOH}$ containing $1.0 \mathrm{M} \mathrm{C}_{2} \mathrm{H}_{5} \mathrm{OH}$ in the potential range from -0.8 to $0.3 \mathrm{~V}$ (vs SCE). Amperometric $i-t$ curves were recorded at a potential of $-0.3 \mathrm{~V}$ (vs SCE) for $1,500 \mathrm{~s}$ in $1.0 \mathrm{M} \mathrm{KOH}$ containing $1.0 \mathrm{M} \mathrm{C}_{2} \mathrm{H}_{5} \mathrm{OH}$ to study the stability test.

\section{RESULTS AND DISCUSSION}

The electrodeposition was carried out in an aqueous solution containing 2.5 wt \% Pluronic P123 and $40 \mathrm{mM} \mathrm{PdCl}_{2}$, without stirring at room temperature for $600 \mathrm{~s}$ and at a constant potential of $0.0 \mathrm{~V}$ vs $\mathrm{Ag} / \mathrm{AgCl}$ (see Experimental Section for more details). Both the top surface and cross-section of the obtained films are imaged by SEM and TEM after carefully removing the surfactants. From the top view, pores uniformly distributed over the entire film can be clearly observed (Figure 1a). The average pore diameter is measured to be $10.9 \mathrm{~nm}$ (calculated from over 200 pores) (Figure $1 \mathrm{~b}$ and Figure S1a and $b$ ). The periodicity of the pore organization is studied by using low-angle XRD revealing a characteristic peak at $0.62^{\circ}$, corresponding to a pore-to-pore distance of $14.2 \mathrm{~nm}$ (Figure S2a). From these results, the average wall thickness is estimated to be $3.3 \mathrm{~nm}$, which is consistent with the average wall thickness obtained statistically from the SEM image (Figure S1c). A cross-section prepared by focused ion beam (FIB) was further studied by high-angle annular dark-field (HAADF) scanning transmission electron microscopy (STEM), suggesting that the porous structure is uniform through the entire thickness of the film (Figure 1c). The typical arc-like 2D GISAXS pattern suggests that the uniformly sized spherical mesopores are randomly packed inside the film (Figure S3a). Furthermore, the plot profile derived from the arc pattern clearly shows a peak centered at $q=0.4 \mathrm{~nm}^{-1}$ (Figure S3b), which corresponds to a pore-to-pore distance of $15.7 \mathrm{~nm}$. Although the pore-to-pore distances obtained from low-angle XRD and GI-SAXS are slightly different, this fact has often been observed in mesoporous films and is due to distortion of the mesoporous film along the perpendicular direction to the substrate. ${ }^{31}$ All the results fully support the formation of a highly uniform mesoporous $\mathrm{Pd}$ film.

The difference in contrast in the cross-sectional TEM image highlights the porous nature of the film and suggests that the pore walls are interconnected (Figure $1 \mathrm{~d}$ and Figure S2b). A typical HRTEM image taken from the edge of the obtained film clearly shows the lattice fringes with a constant $d$-spacing of $0.224 \mathrm{~nm}$, which can be ascribed to the (111) lattice planes of face-centered cubic (fcc) Pd crystals (Figure 1e). The lattice fringes appear to be continuous throughout the interfaces of several particles (Figure S4). The XRD pattern of the mesoporous film contains diffraction peaks located at $40.18^{\circ}$, $46.72^{\circ}, 68.16^{\circ}, 82.18^{\circ}$, and $86.82^{\circ}$ (Figure S2c), which can be assigned to the (111), (200), (220), (311), and (222)
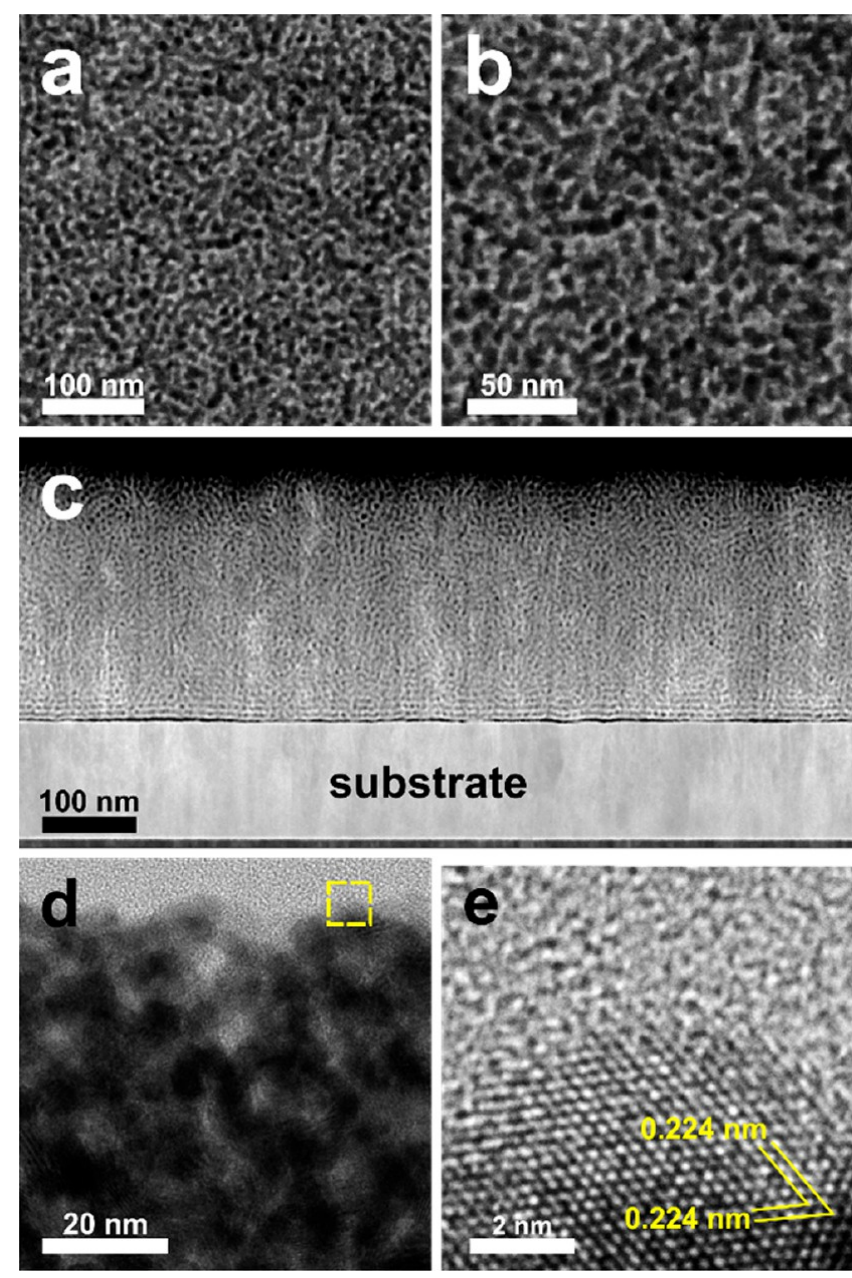

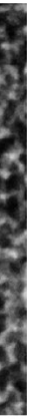

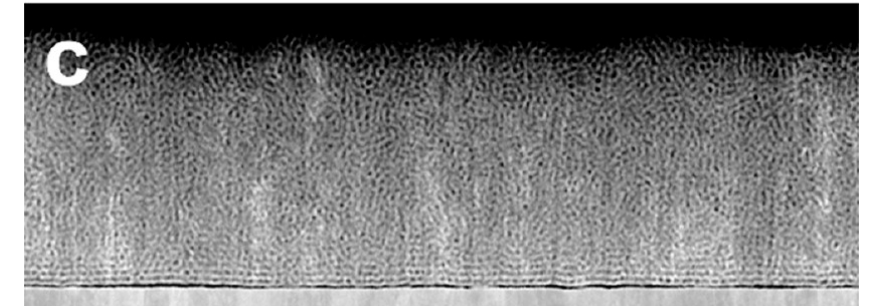

$100 \mathrm{~nm}$ substrate

Figure 1. (a) Low- and (b) high-magnification SEM images showing the top-surface structure of the obtained film. (c) Cross-sectional HAADF-STEM image showing the cross-sectional structure of the obtained film. (d) TEM and (e) HRTEM images showing the crystallinity of the obtained film. The HRTEM image shown in panel (e) is derived from the rectangular area defined in panel (d).

diffraction planes of $\mathrm{Pd}$ with an fcc structure, respectively (JCPDS Card No. 05-0681), supporting our previous HRTEM observations. Figure S5a shows the survey XPS spectra recorded from the mesoporous Pd film surface. The high-resolution spectra of $\mathrm{Pd} 3 \mathrm{~d}$ clearly shows the two peaks at 335.7 and $341 \mathrm{eV}$, which belong to metallic $\mathrm{Pd} 3 \mathrm{~d}_{5 / 2}$ and $\mathrm{Pd}$ $3 \mathrm{~d}_{3 / 2}$, respectively (Figure $\mathrm{S} 5 \mathrm{~b}$ ).

Previously reported mesoporous $\mathrm{Pd}$ films are usually obtained by using cationic surfactants as pore-directing agents because of the suitable interactions between their positive functional group and the $\mathrm{Pd}$ species. ${ }^{10}$ Therefore, the interaction between the nonionic micelles and the Pd species is investigated by using UV-vis spectroscopy and SANS. For the UV-vis investigation, three nonionic surfactants, i.e., Pluronic P123, Pluronic F127, and Brij 58, are mixed with the $\mathrm{PdCl}_{2}$ solution. While establishing the ligand field theory in the 1970 s and $1980 \mathrm{~s},\left[\mathrm{PdCl}_{4-x}\left(\mathrm{H}_{2} \mathrm{O}\right)_{x}\right]^{(-2+x)}$ species resulting from $\mathrm{PdCl}_{2}$ aqueous solution have been determined through optical absorption spectroscopy and DFT calculations to be thermodynamically stable. ${ }^{32-35}$ All the UV-vis spectra exhibit the typical $\mathrm{d}$-d transition of an aqueous solution of $\mathrm{PdCl}_{2}$, consisting of $\left[\mathrm{PdCl}_{4-x}\left(\mathrm{H}_{2} \mathrm{O}\right)_{x}\right]^{(-2+x)}$ ions after $\mathrm{Cl}^{-}$exchange with water molecules (Figure $2 \mathrm{a}$ ). The $\mathrm{d}$-d transitions blue shift 

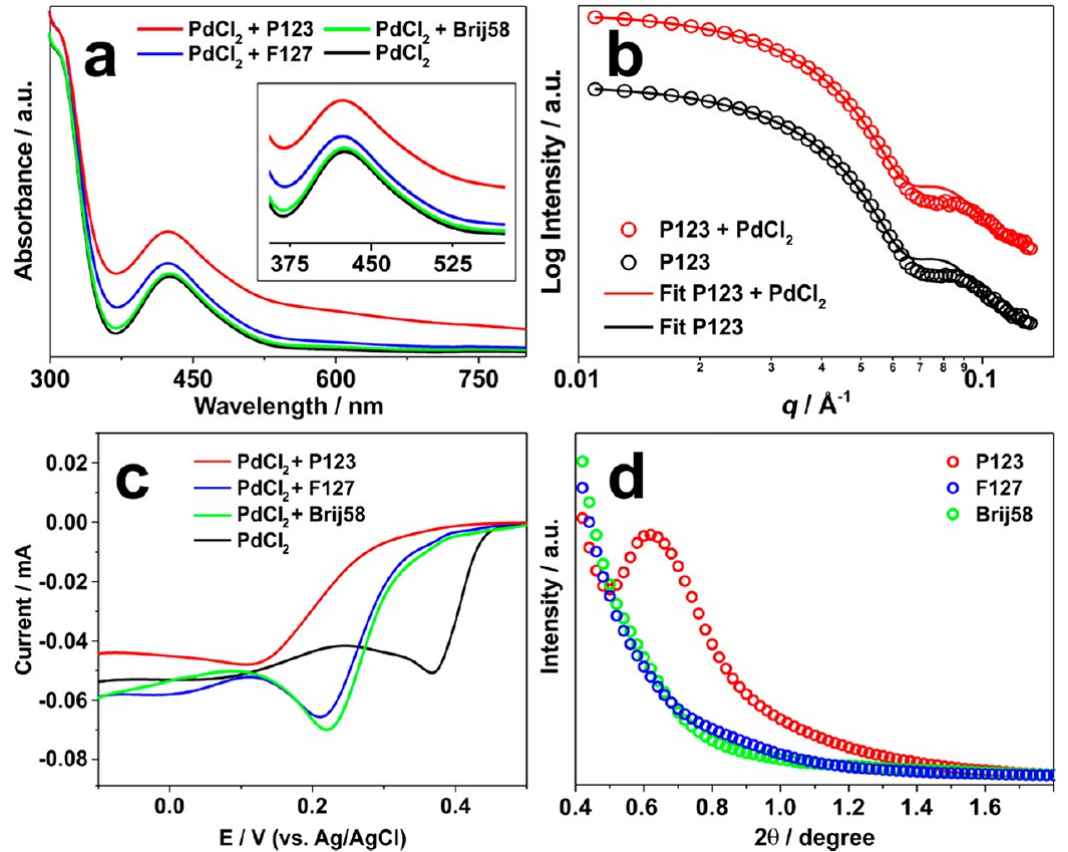

Figure 2. (a) UV-vis spectra of electrolyte solution consisting of various mixtures of nonionic surfactants and $\mathrm{PdCl}_{2}$. (b) SANS data of P123 micelles in solution with appropriate polydisperse spherical fitting. (c) LSV plot recorded at a scan rate of $10 \mathrm{mV} \mathrm{s}^{-1}$ from electrolyte solution consisting of various mixtures of nonionic surfactants and $\mathrm{PdCl}_{2}$. (d) Low-angle $\mathrm{XRD}$ pattern from the Pd film prepared with different surfactants.

with increasing $\mathrm{H}_{2} \mathrm{O}$ content in the coordination sphere. The high energy side of the peak around $400 \mathrm{~nm}$ in the UV-vis spectra is due to a water-rich environment and the low energy side (shoulder) is due to $\mathrm{Cl}^{-}$-rich species. Interestingly, whichever ion goes into the micelle domains also pulls the other ion $\left(\left[\mathrm{Pd}\left(\mathrm{H}_{2} \mathrm{O}\right)_{4}\right]^{2+}\right.$ and $\left.\left[\mathrm{PdCl}_{4}\right]^{2-}\right)$ due to charge balance. The water-coordinated species are interacting with the ethylene oxide moiety of the micelles to drive the $\mathrm{Pd}(\mathrm{II})$ species towards the working electrode surface effectively. The detailed formation mechanism is discussed later.

Pure P123 aqueous solution and $\mathrm{P} 123$ in $40 \mathrm{mM} \mathrm{PdCl}_{2}$ were measured using SANS (Figures S6-S8). The Fourier transform to real space of the SANS data provided in Figure S6 are consistent with P123-forming spherical-shaped micelles, as reported previously. ${ }^{36}$ The scattering data were therefore fit to polydisperse spheres using Igor Pro macros provided by $\mathrm{NIST}^{37}$ assuming the scattering length density to be uniform throughout the micelles (Figure $2 \mathrm{~b}$ ). The diameters of the scattering particles extracted from the spherical fit to the full scattering curves are 13.78 and $13.84 \mathrm{~nm}( \pm 0.04)$ for P123 with and without the metal precursor, respectively, with a polydispersity of $12 \%$. An average diameter of $\sim 14 \mathrm{~nm}$ for P123 micelles in both solvent conditions indicates that the addition of the metal ions (herein, $\mathrm{PdCl}_{2}$ ) does not significantly modify the micelle structure, which is the essence of the micelle assembly approach. Furthermore, the average micelle size and pore diameter observed in the present study are almost consistent with the average pore size reported previously for mesoporous materials synthesized with Pluronic P123 (Table S1). Temperature-dependent data showed a small increase $(<1$ $\mathrm{nm})$ in the diameter of the micelles between 25 and $35{ }^{\circ} \mathrm{C}$ (Figure S7). The linear fit presented in Figure S8 allows the determination of a P123 unimer volume and the aggregation number of the micelles in solution. At $25{ }^{\circ} \mathrm{C}$, the volume of the unimer and an aggregation number were calculated to be 5520 $\AA^{3}$ and 309, respectively.
The surfactant concentration takes a critical role in optimizing the final porous structures as micelles are only formed beyond their critical micelle concentration (CMC). In the present synthesis, the concentration of P123 is fixed at 2.5 wt \% (4.3 mM), which is higher than its CMC value (0.03 wt \% or $0.052 \mathrm{mM}$ at $\left.25{ }^{\circ} \mathrm{C}\right) .{ }^{38}$ In the absence of nonionic surfactant, bulk Pd with a relatively large size is formed (Figure S9a). Below the CMC (i.e., 0.025 wt \%), no porous structure can be observed (Figure 3a), and the surface features become irregular at concentrations of $1.0 \mathrm{wt} \%$ (Figure $3 \mathrm{~b}$ ). When its

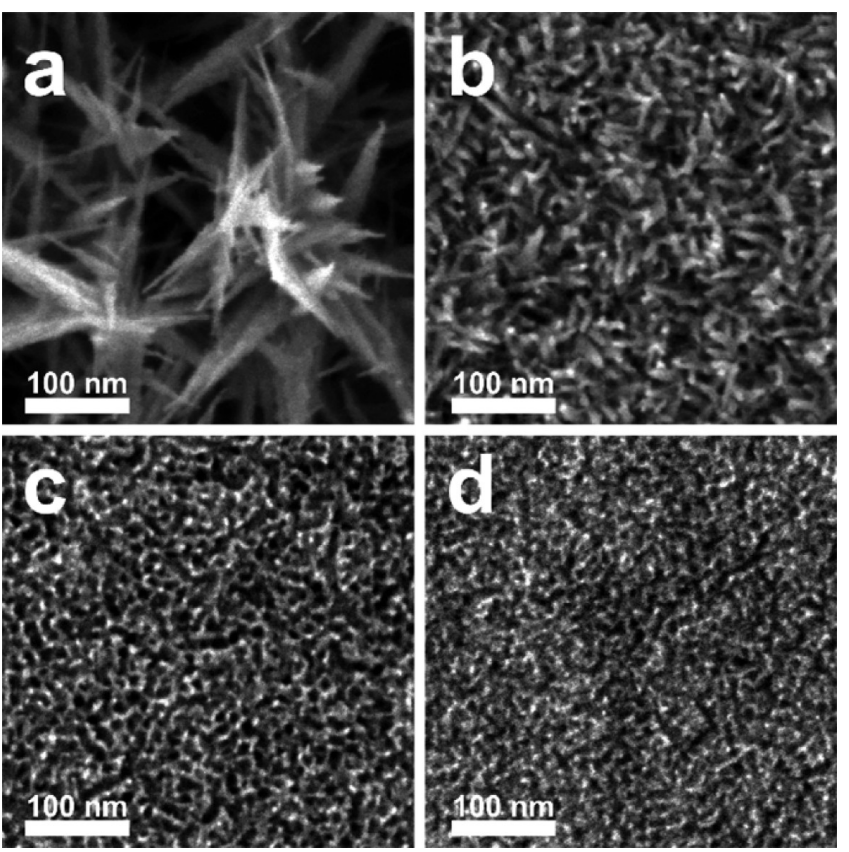

Figure 3. SEM images of Pd films prepared by the typical procedure at concentrations of P123 of (a) 0.025, (b) 1.0, (c) 2.5, and (d) $5.0 \mathrm{wt} \%$. 
concentration is further increased, a well-defined mesoporous structure is obtained (Figures $3 c$ and $d$ ).

The formation mechanism of mesoporous Pd films can be described as follows. As the electrolyte solution is prepared by dissolving P123 in water with a concentration above the CMC, micelles can be assembled. The structure of the P123 micelles, confirmed by SANS, remains undisturbed even after adding the $\mathrm{PdCl}_{2}$ metal precursor. This can be explained by having the water-coordinated Pd ions in the electrolyte solution. A metalaqua complex can interact with the ethylene oxide moiety of the surfactant, as demonstrated by the UV-vis absorption study. The feature at around $400 \mathrm{~nm}$ has been assigned to the $\mathrm{d}$ - $\mathrm{d}$ transition (assigned to the ${ }^{1} \mathrm{~A}_{1 \mathrm{~g}}-{ }^{1} \mathrm{~A}_{2 \mathrm{~g}}$ transition that gradually blue shifts as $x$, the number of $\mathrm{Cl}^{-}$in the coordination sphere, decreases). ${ }^{32}$ The tail of the peak at around $400 \mathrm{~nm}$ originates from the $\mathrm{Cl}^{-}$-rich species (Figure 2a inset). This is a reasonable assumption because $\mathrm{Cl}^{-}$is a relatively weaker field ligand than $\mathrm{H}_{2} \mathrm{O}$. The presence of coordinated water is important for the assembly and interaction with the micelle domains because the charge of the complex varies from $2-$ to $2+$ with increasing water content in the coordination sphere (Pd(II) in all complexes). The complexes interact with the ethylene oxide domains of the surfactant through hydrogen bonding. Notice that the water-rich complexes are positively charged and attracted by the micelles. The negatively charged $\mathrm{Cl}^{-}$-rich complexes are attracted by the positively charged water-rich complexes through electrostatic interactions, thus enhancing the $\mathrm{Pd}(\mathrm{II})$ species content in and around the micelles during the electrodeposition of $\operatorname{Pd}(0)$. The $\mathrm{Pd}$ ions along with the micelles are attracted to the gold-coated silicon wafer substrate (working electrode) driven by the applied potential voltage $(0.0 \mathrm{~V}$ vs $\mathrm{Ag} / \mathrm{AgCl})$. From these descriptions, it is assumed that the Pd films are electrochemically deposited on the working electrode with the assistance of surfactant micelles assembly.

In order to confirm whether other surfactants may be used to form mesoporous Pd films, control experiments are carried out under the same conditions, only replacing P123 with nonionic surfactants of different molecular weights: F127 $\left(\mathrm{EO}_{100}-\mathrm{PO}_{65}\right.$ $\left.\mathrm{EO}_{100}\right)$ and Brij $58\left(\mathrm{C}_{16}-\mathrm{EO}_{20}\right)$. The structures of the obtained films appear to be highly sensitive to the type of surfactant being used. Films deposited with F127 consist of interconnected Pd nanowires, whereas using Brij-58 leads to irregular structures (Figure $\mathrm{S} 9 \mathrm{~b}$ and c, respectively). Linear sweep voltammetry (LSV) was employed to study the electrodeposition process from electrolytes containing different surfactants. The LSV plots obtained at a scan rate of $10 \mathrm{mV}$ $\mathrm{s}^{-1}$ are shown in Figure 2c. The negatively shifted reduction peak of the electrolyte containing P123 compared to that with F127 or Brij 58, indicates that the surfactants stabilize Pd(II) more efficiently. Both F127 and Brij 58 have large ethylene oxide units compared to those with P123. Consequently, their respective micelles are expected to be less stable than for P123. The hydrophobic core (PO units) of $\mathrm{P} 123$ provides stability to the micelles while the hydrophilic shell (EO block) accommodates the dissolved metal species. Low-angle XRD patterns of the Pd films prepared by F127 and Brij 58 have no distinct peaks (Figure 2d). All these results indicate that only P123 can act as pore-directing agent in the preparation of mesoporous Pd films, under our depostion conditions.

The effect of the applied potential on the mesoporous structure ordering of the $\mathrm{Pd}$ film is investigated, ranging from -0.3 to $0.0 \mathrm{~V}$ (vs $\mathrm{Ag} / \mathrm{AgCl}$ ). The deposition potential affects the current passing through the working electrode. ${ }^{39,40}$ A more negative voltage leads to a higher current, promoting higher reduction rate of the metal ions associated with the surfactant micelles. The reduction rate is critical to obtain porous structures. Beyond a certain threshold, the reduction rate usually breaks down the micellar template. ${ }^{41}$ The structure of the obtained $\mathrm{Pd}$ films gradually changes from dendritic $(-0.3 \mathrm{~V}$ vs $\mathrm{Ag} / \mathrm{AgCl}$ ) to porous (0.0 V vs $\mathrm{Ag} / \mathrm{AgCl}$ ) (Figure 4). The
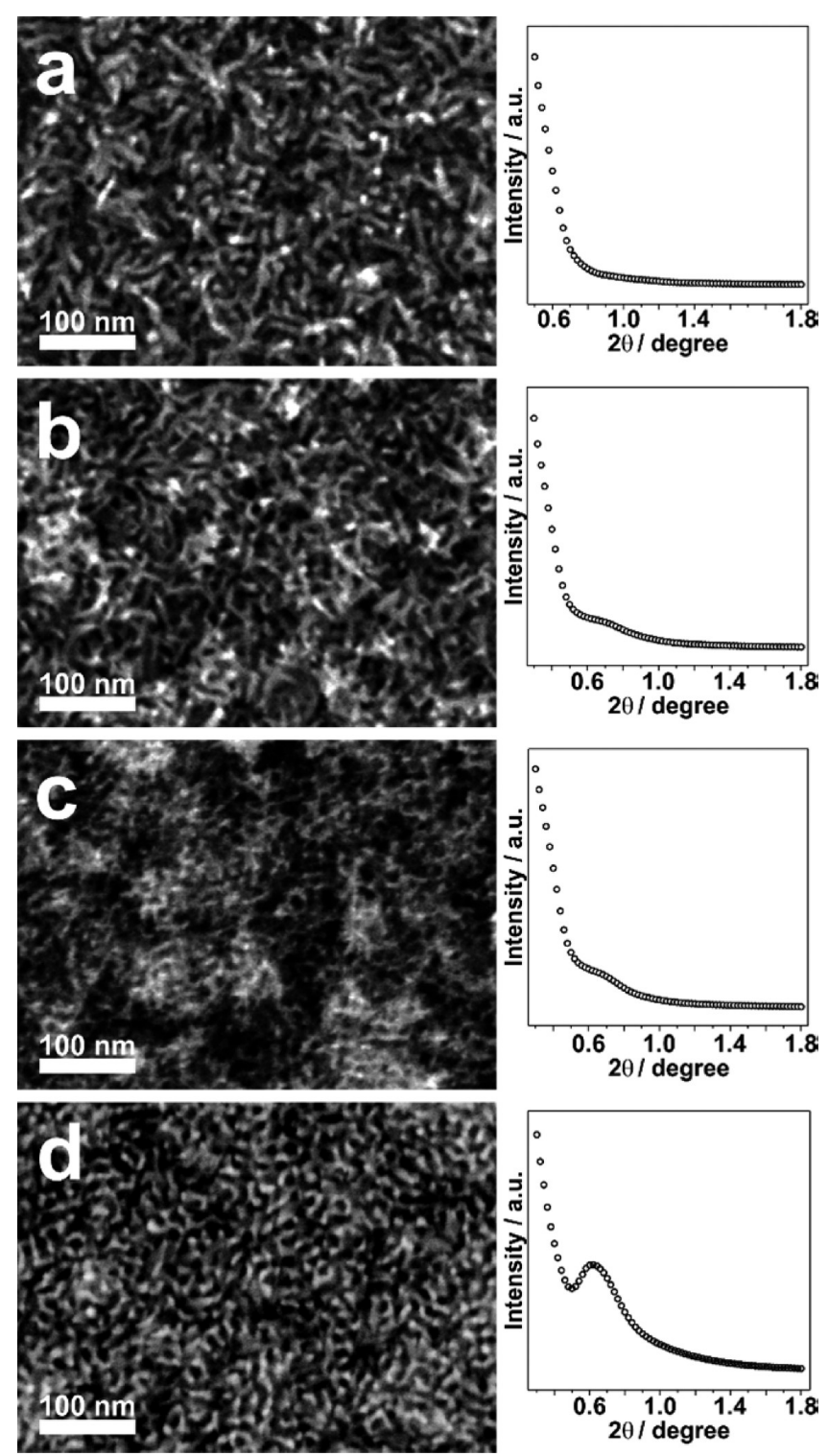

Figure 4. Top-surface SEM images (left) and low-angle XRD pattern (right) of Pd films prepared with P123 at electrodeposition potentials of (a) -0.3 , (b) -0.2 , (c) -0.1 , and (d) $0.0 \mathrm{~V}$ vs Ag/AgCl.

intensity of the peak shown in the low-angle XRD patterns gradually increases as the potential becomes closer to $0.0 \mathrm{~V}$, indicating an enhanced pore ordering. Furthermore, at potentials higher than $0.0 \mathrm{~V}$ vs $\mathrm{Ag} / \mathrm{AgCl}$ (e.g., $0.1 \mathrm{~V}$ ), the mesoporous structure ordering decreases due a slower reduction rate (Figure S10). Therefore, the surfactant concentration and the applied electrodeposition potential are critical factors to ensure optimized quality of the mesoporous structure ordering. 

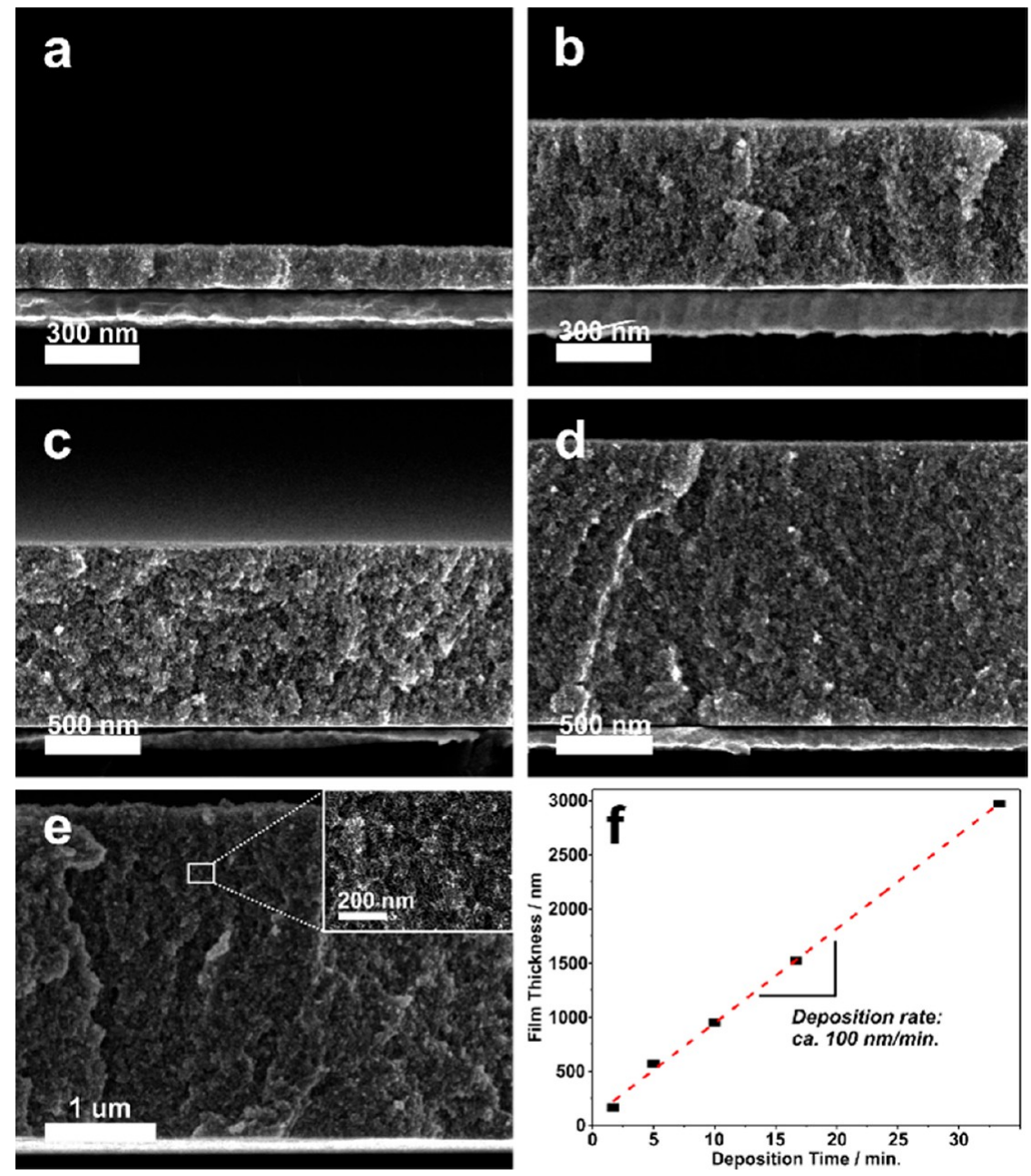

Figure 5. Cross-sectional SEM images of mesoporous Pd films prepared at deposition times of (a) 100, (b) 300, (c) 600, (d) 1000, and (e) $2000 \mathrm{~s}$. (f) Relation between the film thickness and the deposition time.
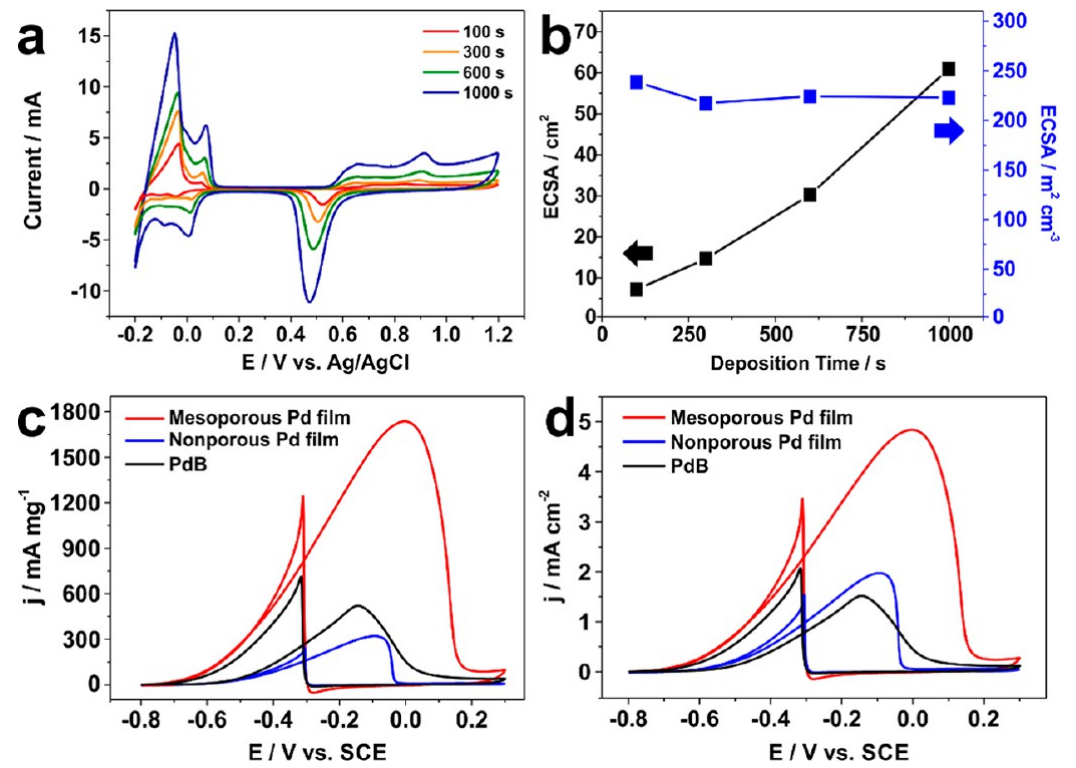

Figure 6. (a) CV measurements of the mesoporous Pd films prepared at various deposition times in $0.5 \mathrm{M} \mathrm{H}_{2} \mathrm{SO}_{4}$. (b) Relation between the deposition time and ECSA and volume-normalized ECSA. (c) Pd mass-normalized and (d) ECSA-normalized CV curves of the mesoporous Pd film, nonporous $\mathrm{Pd}$ film, and commercial $\mathrm{PdB}$ in $1 \mathrm{M} \mathrm{KOH}$ containing $1 \mathrm{M} \mathrm{C}_{2} \mathrm{H}_{5} \mathrm{OH}$. All the $\mathrm{CV}$ curves were obtained at a scan rate of $50 \mathrm{mV} \mathrm{s}{ }^{-1}$. 
The catalytic activity of the mesoporous films is not only influenced by the pore size but also by the film thickness. The electrochemical approach can be easily tuned to control film thickness by simply changing the deposition time. The film thickness is carefully studied through cross-sectional SEM observations (Figure $5 \mathrm{a}-\mathrm{e}$ ). The film thickness linearly increases with the deposition time with a growth rate of 100 $\mathrm{nm} \mathrm{min}^{-1}$ until the entire metal precursor is depleted from the electrolyte (Figure 5f). For comparison, the growth rate of nonporous Pd films is $\sim 210 \mathrm{~nm} \mathrm{~min}{ }^{-1}$. The amount of metallic Pd deposited on the working electrode can be calculated theoretically by Faraday's first law of electrolysis and is used to describe its linear relationship with the deposition time. ${ }^{42}$ It dictates that the amounts of deposited substance are directly proportional to the number of passing charges $(m \propto Q)$. The current density passing through the working electrode at a specific applied potential is constant, independently from the deposition time. Furthermore, the estimated mass of deposited Pd can be estimated through eq 1 .

$$
m=\left(\frac{Q}{F}\right)\left(\frac{M}{z}\right)
$$

where $m$ is the mass of substance deposited on the electrode, $Q$ is the total electric charge passed through the substance, $F$ is the Faraday constant $\left(96485 \mathrm{C} \mathrm{mol}^{-1}\right), M$ is the molar mass of the substance, and $z$ is the valence number of ions involved in the reduction reaction. The relationship plot between the deposition time and theoretical amount (mass) of deposited substance is presented in Figure S11, along with the actual mass of deposited Pd measured with a precision balance, suggesting that the deposition efficiency is around 99\%. The film morphology appears to be independent from the deposition time, as observed by SEM (Figure S12).

The influence of the film thickness on mass transport is studied by using the electrochemical surface area (ECSA). Four typical samples with deposition times of 100, 300, 600, and $1000 \mathrm{~s}$ are selected for the study. The ECSA investigation is carried out by the cyclic voltammetric (CV) in $0.5 \mathrm{M} \mathrm{H}_{2} \mathrm{SO}_{4}$ with a scan rate of $50 \mathrm{mV} \mathrm{s}^{-1}$ in a potential ranging from -0.2 to $1.2 \mathrm{~V}$ (vs $\mathrm{Ag} / \mathrm{AgCl}$ ). The ECSA is estimated by calculating the oxide reduction charge assuming that the conversion factor for an oxide monolayer reduction is $420 \mu \mathrm{C} \mathrm{cm}^{-2}$ on a smooth Pd surface. ${ }^{43}$ As the film thickness increases, the reduction peak of $\mathrm{PdO}$, located between 0.3 and $0.7 \mathrm{~V}$ (vs $\mathrm{Ag} / \mathrm{AgCl}$ ), increases (Figure 6a). The ECSAs are measured to be 7.17, 14.66, 30.28, and $60.95 \mathrm{~cm}^{2}$ for deposition times of $100,300,600$, and 1000 $\mathrm{s}$, respectively. The ECSA linearly increases as the film thickness increases (Figure 6b, black line). Interestingly, the ECSA normalized by the geometric volume of the film remains relatively constant (Figure $6 \mathrm{~b}$, blue line), indicating that the large surface area derived from the mesoporous structure inside the film is fully accessible. The mass-normalized ECSA of mesoporous Pd films is calculated to be $37.85 \mathrm{~m}^{2} \mathrm{~g}^{-1}$, which is 10-times higher than those of the nonporous Pd film $\left(3.56 \mathrm{~m}^{2}\right.$ $\left.\mathrm{g}^{-1}\right)$ and commercial $\mathrm{PdB}\left(3.43 \mathrm{~m}^{2} \mathrm{~g}^{-1}\right)$.

$\mathrm{Pd}$ is known to be promising for the catalysis of the oxidation reaction of fuel molecules in alkaline solution, even compared to Pt. In order to evaluate the electrocatalytic activity of the asprepared mesoporous Pd films, ethanol oxidation reaction was selected as a model reaction in electrolyte of $1.0 \mathrm{M} \mathrm{KOH}$ containing 1.0 $\mathrm{M} \mathrm{C}_{2} \mathrm{H}_{5} \mathrm{OH}$. For comparison, a nonporous $\mathrm{Pd}$ film (as shown in Figure 3a) with the same deposition time (100 s) and Pd black (abbreviated as PdB) are also studied.
The CV curves of the Pd films in forward scan (scan rate of 50 $\mathrm{mV} \mathrm{s}^{-1}$ ) showed different current peak positions compared to that of commercial PdB (Figure 6c). This uncommon shape can be ascribed to the effect of the gold substrate as a working electrode instead of glassy carbon electrode (GCE). The massnormalized activity of the mesoporous $\mathrm{Pd}$ film is found to be as high as $1735.0 \mathrm{~mA} \mathrm{mg}{ }^{-1}$, which is 5.4- and 2.4-times higher than those of the nonporous Pd film $\left(320.9 \mathrm{~mA} \mathrm{mg}^{-1}\right)$ and $\mathrm{PdB}$ $\left(710.6 \mathrm{~mA} \mathrm{mg}^{-1}\right)$, respectively (Figure 6c). Even when normalized by the respective ECSAs of the samples, the CV curves of the mesoporous Pd film sample exhibit remarkable peak current density compared to those of both nonporous $\mathrm{Pd}$ film and PdB. The superior catalytic activity is ascribed to the enhanced exposure of the active surface. The catalytic stability was then evaluated by amperometric $i-t$ method at $-0.3 \mathrm{~V}$ (vs SCE) for $1500 \mathrm{~s}$. The results showcase the superior stability of the mesoporous Pd film (Figure S13a). SEM images obtained after the stability test suggest that the mesoporous Pd film sample can retain its porosity, whereas the nonporous Pd film undergoes significant structural changes (Figure S13b and c). The porous structure, being accessible both from the surface and from the inside, is believed to be responsible for enhancing the electrocatalytic activity.

\section{CONCLUSIONS}

In this work, we successfully prepared mesoporous Pd films containing abundant accessible active sites for electrocatalytic applications such as electrooxidation of ethanol. SANS data showed that the Pluronic P123 micelles formed via selfassembly are not altered by the addition of the metal precursor. The interaction between the head moiety of the micelles and the metal ions, $\left[\mathrm{PdCl}_{4-x}\left(\mathrm{H}_{2} \mathrm{O}\right)_{x}\right]^{-2+x}$, was confirmed through optical analysis. During the electrodeposition of the mesoporous films, the metal ions are attracted and subsequently reduced by the applied potential. Morphological studies suggest that the pores are formed over the entire film, have an average pore diameter of $10.9 \mathrm{~nm}$, and are continuously spanning throughout the thickness. The surfactant concentration and applied deposition potential are key factors for optimizing the formation of homogeneous and well-distributed pores. The use of nonionic surfactants in such an electrodeposition process provides easy routes to template removal. The preparation of this pure crystalline mesoporous Pd film is a proof of concept that can be easily expanded to other metals or alloys and is beneficial for the fabrication of microfuel cells as an on-chip power source device.

\section{ASSOCIATED CONTENT}

\section{Supporting Information}

The Supporting Information is available free of charge on the ACS Publications website at DOI: 10.1021/acs.chemmater.7b01811.

Additional SEM and TEM images, XPS spectra, low- and wide-angle XRD patterns, GI-SAXS patterns, and distribution histograms of pore size and pore wall thickness of the mesoporous Pd films; small-angle neutron-scattering on micellar solutions; relationship between Pd mass deposited on the working electrode and the deposition time; and amperometric $i-t$ curve of mesoporous Pd film, nonporous Pd film, and PdB for the catalytic stability test (PDF) 


\section{AUTHOR INFORMATION}

\section{Corresponding Author}

*E-mail: yusuke@uow.edu.au.

\section{ORCID}

Ömer Dag: 0000-0002-1129-3246

Yusuke Yamauchi: 0000-0001-7854-927X

\section{Notes}

The authors declare no competing financial interest.

\section{ACKNOWLEDGMENTS}

This work was partly supported by an Australian Research Council (ARC) Future Fellow (FT150100479), the ANSTOUOW 2016 grant, and the AIIM-MANA 2016 grant. M.I. also would like to thank the Indonesia Endowment Fund for Education (LPDP) for the financial support. The authors would like to thank Pore Fabrication Pty Ltd (Australia) for helpful suggestion and discussion.

\section{REFERENCES}

(1) Davis, M. Ordered Porous Materials for Emerging Applications. Nature 2002, 417, 813-821.

(2) Innocenzi, P.; Malfatti, L. Mesoporous Thin Films: Properties and Applications. Chem. Soc. Rev. 2013, 42, 4198-4216.

(3) Shao, S.; Wu, H.; Wang, S.; Hong, Q.; Koehn, R.; Wu, T.; Rao, W.-F. Highly Crystalline and Ordered Nanoporous $\mathrm{SnO}_{2}$ Thin Films with Enhanced Acetone Sensing Property at Room Temperature. J. Mater. Chem. C 2015, 3, 10819-10829.

(4) Bastakoti, B.; Ishihara, S.; Leo, S.-Y.; Ariga, K.; Wu, K.-W.; Yamauchi, Y. Polymeric Micelle Assembly for Preparation of LargeSized Mesoporous Metal Oxides with Various Compositions. Langmuir 2014, 30, 651-659.

(5) Martens, J.; Jammaer, J.; Bajpe, S.; Aerts, A.; Lorgouilloux, Y.; Kirschhock, C. Simple Synthesis Recipes of Porous Materials. Microporous Mesoporous Mater. 2011, 140, 2-8.

(6) Wang, H.; Wang, L.; Sato, T.; Sakamoto, Y.; Tominaka, S.; Miyasaka, K.; Miyamoto, N.; Nemoto, Y.; Terasaki, O.; Yamauchi, Y. Synthesis of Mesoporous Pt Films with Tunable Pore Sizes from Aqueous Surfactant Solutions. Chem. Mater. 2012, 24, 1591-1598.

(7) Fu, S.; Zhu, C.; Song, J.; Engelhard, M. H.; Xia, H.; Du, D.; Lin, Y. Kinetically Controlled Synthesis of Pt-Based One-Dimensional Hierarchically Porous Nanostructures with Large Mesopores as Highly Efficient ORR Catalysts. ACS Appl. Mater. Interfaces 2016, 8, 3521335218.

(8) Franceschini, E. A.; Bruno, M. M.; Williams, F. J.; Viva, F. A.; Corti, H. R. High-Activity Mesoporous $\mathrm{Pt} / \mathrm{Ru}$ Catalysts for Methanol Oxidation. ACS Appl. Mater. Interfaces 2013, 5, 10437-10444.

(9) Sun, T.; Zhang, C.; Chen, J.; Yan, Y.; Zakhidov, A. A.; Baughman, R. H.; Xu, L. Three-dimensionally Ordered Macro-/mesoporous Ni as a Highly Efficient Electrocatalyst for the Hydrogen Evolution Reaction. J. Mater. Chem. A 2015, 3, 11367-11375.

(10) Li, C.; Jiang, B.; Miyamoto, N.; Kim, J. H.; Malgras, V.; Yamauchi, Y. Surfactant-Directed Synthesis of Mesoporous Pd Films with Perpendicular Mesochannels as Efficient Electrocatalysts. J. Am. Chem. Soc. 2015, 137, 11558-11561.

(11) Hao, M.; Wu, S.; Zhou, H.; Ye, W.; Wei, X.; Wang, X.; Chen, Z.; Li, S. Room-Temperature and Fast Response Hydrogen Sensor Based on Annealed Nanoporous Palladium Film. J. Mater. Sci. 2016, 51, $2420-2426$.

(12) Wang, H.; Imura, M.; Nemoto, Y.; Park, S. E.; Yamauchi, Y. Synthesis of Olive-Shaped Mesoporous Platinum Nanoparticles (MPNs) with Hard-Templating Method Using Mesoporous Silica (SBA-15). Chem. - Asian J. 2012, 7, 802-808.

(13) Wang, H.; Jeong, Y.; Imura, M.; Wang, L.; Radhakrishnan, L.; Fujita, N.; Castle, T.; Terasaki, O.; Yamauchi, Y. Shape- and SizeControlled Synthesis in Hard-Templates: Sophisticated Chemical
Reduction for Mesoporous Monocrystalline Platinum Nanoparticles. J. Am. Chem. Soc. 2011, 133, 14526-14529.

(14) Du, C.; Chen, M.; Wang, W.; Yin, G. Nanoporous PdNi Alloy Nanowires as Highly Active Catalysts for the Electro-Oxidation of Formic Acid. ACS Appl. Mater. Interfaces 2011, 3, 105-109.

(15) Li, W. C.; Balk, T. Preparation and Hydrogen Absorption/ Desorption of Nanoporous Palladium Thin Films. Materials 2009, 2, 2496-2509.

(16) Tominaka, S.; Hayashi, T.; Nakamura, Y.; Osaka, T. Mesoporous PdCo Sponge-like Nanostructure Synthesized by Electrodeposition and Dealloying for Oxygen Reduction Reaction. J. Mater. Chem. 2010, 20, 7175-7182.

(17) Denuault, G.; Milhano, C.; Pletcher, D. Mesoporous PalladiumThe Surface Electrochemistry of Palladium in Aqueous Sodium Hydroxide and the Cathodic Reduction of Nitrite. Phys. Chem. Chem. Phys. 2005, 7, 3545-3551.

(18) Al Abass, N. A.; Denuault, G.; Pletcher, D. The Unexpected Activity of Pd Nanoparticles Prepared Using a Non-Ionic Surfactant Template. Phys. Chem. Chem. Phys. 2014, 16, 4892-4899.

(19) Choi, K. S.; McFarland, E. W.; Stucky, G. D. Electrocatalytic Properties of Thin Mesoporous Platinum Films Synthesized Utilizing Potential-Controlled Surfactant Assembly. Adv. Mater. 2003, 15, 2018-2021.

(20) Song, Y.; Yang, Y.; Medforth, C. J.; Pereira, E.; Singh, A. K.; Xu, H.; Jiang, Y.; Brinker, C. J.; van Swol, F.; Shelnutt, J. A. Controlled Synthesis of 2-D and 3-D Dendritic Platinum Nanostructures. J. Am. Chem. Soc. 2004, 126, 635-645.

(21) Wang, F.; Li, C.; Sun, L.-D.; Xu, C.-H.; Wang, J.; Yu, J. C.; Yan, C.-H. Porous Single-Crystalline Palladium Nanoparticles with High Catalytic Activities. Angew. Chem., Int. Ed. 2012, 51, 4872-4876.

(22) Jiang, B.; Li, C.; Malgras, V.; Imura, M.; Tominaka, S.; Yamauchi, Y. Mesoporous Pt Nanospheres with Designed Pore Surface as Highly Active Electrocatalyst. Chem. Sci. 2016, 7, 15751581.

(23) Sun, L.; Wang, H.; Eid, K.; Wang, L. Shape-controlled Synthesis of Porous AuPt Nanoparticles and Their Superior Electrocatalytic Activity for Oxygen Reduction Reaction. Sci. Technol. Adv. Mater. 2016, 17, 58-62.

(24) Shih, Z. Y.; Wang, C. W.; Xu, G.; Chang, H. T. Porous Palladium Copper Nanoparticles for the Electrocatalytic Oxidation of Methanol in Direct Methanol Fuel Cells. J. Mater. Chem. A 2013, 1, 4774-4778.

(25) Li, C.; Sato, T.; Yamauchi, Y. Size-controlled Synthesis of Mesoporous Palladium Nanoparticles as Highly Active and Stable Electrocatalysts. Chem. Commun. 2014, 50, 11753-11756.

(26) Kalekar, A. M.; Sharma, K. K. K.; Luwang, M. N.; Sharma, G. K. Catalytic Activity of Bare and Porous Palladium Nanostructures in the Reduction of 4-nitrophenol. RSC Adv. 2016, 6, 11911-11920.

(27) Bagshaw, S. A.; Prouzet, E.; Pinnavaia, T. J. Templating of Mesoporous Molecular Sieves by Nonionic Polyethylene Oxide Surfactants. Science 1995, 269, 1242-1244.

(28) Calleja, G.; Serrano, D. R.; Sanz, R.; Pizarro, P.; Garcia, A. Study on the Synthesis of High-Surface-Area Mesoporous $\mathrm{TiO}_{2}$ in the Presence of Nonionic Surfactants. Ind. Eng. Chem. Res. 2004, 43, 2485-2492.

(29) Sokolova, A.; Christoforidis, J.; Eltobaji, A.; Barnes, J.; Darmann, F.; Whitten, A. E.; de Campo, L. Time-of-Flight Small Angle Scattering Instrument. Neutron News 2016, 27, 9-13.

(30) Arnold, O.; Bilheux, J. C.; Borreguero, J. M.; Buts, A.; Campbell, S. I.; Chapon, L.; Doucet, M.; Draper, N.; Ferraz Leal, R.; Gigg, M. A.; Lynch, V. E.; Markvardsen, A.; Mikkelson, D. J.; Mikkelson, R. L.; Miller, R.; Palmen, K.; Parker, P.; Passos, G.; Perring, T. G.; Peterson, P. F.; Ren, S.; Reuter, M. A.; Savici, A. T.; Taylor, J. W.; Taylor, R. J.; Tolchenov, R.; Zhou, W.; Zikovsky, J. Mantid-Data analysis and visualization package for neutron scattering and $\mu \mathrm{SR}$ experiments. Nucl. Instrum. Methods Phys. Res., Sect. A 2006, 764, 156-166.

(31) Yamauchi, Y.; Sawada, M.; Sugiyama, A.; Osaka, T.; Sakka, Y.; Kuroda, K. Magnetic-Induced Orientation of Mesochannels in 2D- 
Hexagonal Mesoporous Silica Films. J. Mater. Chem. 2006, 16, 36933700.

(32) Elding, L. I.; Olsson, L. F. Electronic absorption spectra of square-planar chloro-aqua and bromo-aqua complexes of palladium(II) and platinum(II). J. Phys. Chem. 1978, 82, 69-74.

(33) Deeth, R. J.; Elding, L. I. Theoretical modelling of water exchange on $\left[\mathrm{Pd}\left(\mathrm{H}_{2} \mathrm{O}\right)_{4}\right]^{2+},\left[\mathrm{Pt}\left(\mathrm{H}_{2} \mathrm{O}\right)_{4}\right]^{2+}$, and trans- $\left[\mathrm{PtCl}_{2}\left(\mathrm{H}_{2} \mathrm{O}\right)_{2}\right]$. Inorg. Chem. 1996, 35, 5019-5026.

(34) Mech, K.; Zabinski, P.; Kowalik, R.; Fitzner, K. Kinetics and mechanism of $\left[\mathrm{PdCl}_{\mathrm{x}}\left(\mathrm{H}_{2} \mathrm{O}\right)_{4-\mathrm{x}}\right]^{2-\mathrm{x}}(\mathrm{x}=3,4)$ complexes electroreduction. J. Electrochem. Soc. 2013, 160, H770-H774.

(35) Podborska, A.; Wojnicki, M. Spectroscopic and theoretical analysis of $\mathrm{Pd}^{2+}-\mathrm{Cl}^{-}-\mathrm{H}_{2} \mathrm{O}$ system. J. Mol. Struct. 2017, 1128, 117-122.

(36) Liu, Y.; Chen, S. H.; Huang, J. S. Small-Angle Neutron Scattering Analysis of the Structure and Interaction of Triblock Copolymer Micelles in Aqueous Solution. Macromolecules 1998, 31, 2236-2244.

(37) Kline, S. R. Reduction and Analysis of SANS and USANS Data using Igor Pro. J. Appl. Crystallogr. 2006, 39, 895-900.

(38) Alexandridis, P.; Holzwarth, J. F.; Hatton, T. A. Micellization of Poly(ethylene oxide)-Poly(propylene oxide)-Poly(ethylene oxide) Triblock Copolymers in Aqueous Solutions: Thermodynamics of Copolymer Association. Macromolecules 1994, 27, 2414-2425.

(39) Shen, C. M.; Zhang, X. G.; Li, H. L. Influence of Different Deposition Potentials on Morphology and Structure of CdSe Films. Appl. Surf. Sci. 2005, 240, 34-41.

(40) Malek, S. N. A.; Mohd, Y. Effect of Deposition Potential on the Structure, Electrocatalytic Activity and Stability of Pt Films for Methanol Oxidation. Int. J. Electrochem. Sci. 2017, 12, 1561-1571.

(41) Elliott, J. M.; Attard, G. S.; Bartlett, P. N.; Coleman, N. R. B.; Merckel, D. A. S.; Owen, J. R. Nanostructured Platinum $\left(\mathrm{H}_{\mathrm{I}}-\mathrm{ePt}\right)$ Films: Effects of Electrodeposition Conditions on Film Properties. Chem. Mater. 1999, 11, 3602-3609.

(42) Ehl, R. G.; Ihde, A. Faraday's Electrochemical Laws and the Determination of Equivalent Weights. J. Chem. Educ. 1954, 31, 226232.

(43) Kadirgan, F.; Beden, B.; Leger, J. M.; Lamy, C. Synergistic Effect in the Electrocatalytic Oxidation of Methanol on Platinum+Palladium Alloy Electrodes. J. Electroanal. Chem. Interfacial Electrochem. 1981, $125,89-103$. 